\title{
Phenotypical Characteristics of Group B Streptococcus in Parturients
}

\author{
Jose Antonio Simoes ${ }^{1}$, Valeria Moraes Neder Alves², Sergio Eduardo Longo Fracalanzza ${ }^{3}$, Rodrigo Pauperio Soares de Camargo ${ }^{2}$, \\ Lenir Mathias ${ }^{2}$, Helaine Maria Besteti Pires Milanez ${ }^{1}$ and Eliane Melo Brolazo ${ }^{1}$ \\ ${ }^{1}$ Department of Obstetrics and Gynecology, School of Medical Sciences, State University of Campinas (Unicamp); Campinas, SP; \\ ${ }^{2}$ Department of Obstetrics and Gynecology, School of Medicine of Jundiaí; Jundiaí, SP; \\ ${ }^{3}$ Institute of Microbiology, Federal University of Rio de Janeiro; Rio de Janeiro, RJ, Brazil
}

\begin{abstract}
Colonization by Group B Streptococcus (GBS) is highly prevalent among pregnant women, with prevalence rates ranging between $4 \%$ and $30 \%$. The infection may be transmitted vertically and may result in serious neonatal consequences. In the period from November 2003 to May 2004, a cross-sectional study was carried out among 316 parturients at the Jundiaí Teaching Hospital to establish the prevalence of genital GBS colonization, to identify the factors associated with colonization and the characteristic phenotypes of these streptococci. Samples from rectal and vaginal areas were collected for selective culture in Todd-Hewitt broth. Susceptibility to 7 antimicrobial agents was tested using the antibiotic diffusion disk technique, and the isolated strains were classified using specific antisera. The prevalence of GBS colonization was $14.6 \%$. No strain was resistant to penicillin, ampicillin, erythromycin or nitrofurantoin. The majority of strains were sensitive to cephalothin. Greatest resistance was to gentamicin (76.1\%), followed by clindamycin (17.4\%). The most frequent serotype was Ib $(23.9 \%)$, followed by serotypes II and Ia (19.6\% and $\mathbf{1 7 . 4 \%}$, respectively). There was no correlation between serotype and greater antimicrobial resistance. In conclusion, the prevalence of GBS in parturients was high and penicillin continues to be the drug of choice for intrapartum prophylaxis. The most frequent serotype (Ib) found in this study differs from those found in the majority of studies carried out in other countries, revealing the need to identify prevalent serotypes in each region so that specific vaccines can be designed.
\end{abstract}

Key-Words: Streptococcus agalactiae, neonatal infections, antimicrobial resistance, serum type, GBS, pregnant woman.

Worldwide, colonization by Group B Streptococcus (GBS) is highly prevalent among pregnant women, varying between $4 \%$ and 30\% [1-3]. In Brazil, there are few publications on this subject, and some authors have found a GBS isolation rate of 4-25\% among Brazilian parturients [4-10]. Rates of colonization may vary greatly according to the sample collection site, the culture medium used, the ethnic group, geographical location, immunological factors and the age of the population investigated [11-13].

With the objective of reducing neonatal morbidity and mortality due to GBS, different countries have implemented strategies of intrapartum prophylactic antibiotic therapy, resulting in a significant decrease in the incidence of neonatal infection from 2.7 to 0.4 per 1,000 live births [14-17]. Penicillin is recommended for intrapartum prophylaxis, with ampicillin as an alternative [14]. In patients with a history of allergy to penicillin and at high risk for anaphylaxis, clindamycin or erythromycin have been recommended as the drugs of choice $[14,18]$. However, prevention and treatment strategies have not yet been adopted in Brazil to reduce the incidence of neonatal infection by GBS [6,19].

Received on 24 September 2006; revised 11 February 2007.

Address for correspondence: Prof. Dr. José Antonio Simoes. Caixa Postal: 6181, Cidade Universitária Zeferino Vaz, Zip code: 13.083970, Campinas, São Paulo, Brazil. Telephone: 55(19)3289-2856/ 37889306 Fax: 55(19) 3289-2440. E-mail: jsimoes@caism.unicamp.br. Financial Support: Fundação de Amparo à Pesquisa do Estado de São Paulo (FAPESP) Grant No. 13223-3.

The Brazilian Journal of Infectious Diseases

2007;11(2):261-266. (C) 2007 by The Brazilian Journal of Infectious Diseases and Contexto Publishing. All rights reserved.
Antimicrobial susceptibility and serological classification, i.e. serotyping, have been cited as the principal phenotypical characteristics of GBS [20]. With respect to antimicrobial susceptibility, studies have shown that most cases present no resistance of GBS to penicillin $[21,22]$. On the other hand, resistance to other antibiotics has been frequently described $[23,24]$. It should be emphasized that resistance to an antimicrobial agent increases over time, differs between serotypes and varies according to geographical location, which leads to the conclusion that the choice of the best antimicrobial agent should be guided by the pattern of antibiotic resistance observed in each geographical region [22].

In addition to chemoprophylaxis, immunoprophylaxis has also been suggested for the prevention of GBS infection [25] and to make the development of a vaccine possible, knowledge of the most important serotypes in the region in question is vital [5]. Eleven serotypes have been described according to the capsular polysaccharide antigen, of which the serotypes most frequently found have been serotypes I and II $[26,27]$.

The objective of this study was to evaluate the prevalence of vaginal and rectal GBS colonization in parturients, to identify factors associated with this colonization and to describe the phenotypical characteristics of these streptococci (antimicrobial susceptibility and serotyping).

\section{Materials and Methods}

This is a cross-sectional study involving 316 parturients admitted to the Jundiaí Teaching Hospital between November 11, 2003 and May 14, 2004. Sample size was estimated considering a prevalence of $4 \%$ to $20 \%$, a sample error of $3.8 \%$ 
and a confidence interval of $95 \%$. The study was approved by the IRB of the State University of Campinas, Brazil (UNICAMP), and all participants signed an informed consent form prior to admission. Exclusion criteria comprised: use of antimicrobial medication in the 2 weeks prior to admission, and being at a very advanced stage of labor with delivery imminent, making it impossible to carry out the laboratory tests required by the protocol. Data regarding risk factors were obtained from the routine hospital records or directly from the patients and transcribed onto the form specifically designed for the study.

At the time of the admission exam and prior to carrying out any perineal antisepsis, samples from the lower vagina and rectum (through the anal sphincter) were collected using 2 sterile swabs. Both swabs were immediately placed in selective enrichment broth (Todd-Hewitt) and sent to the Laboratory of Microbiology.

At the laboratory, samples were incubated for 24 hours at $37^{\circ} \mathrm{C}$ in a $5 \% \mathrm{CO}_{2}$ atmosphere. Colonies of beta-hemolytic streptococci and Gram-positive diplococci were plated onto blood agar and incubated for 16 to 18 hours, after which they were identified by the negative catalase test process. After obtaining a purified GBS culture, identified both by the presence of hemolysis and negative catalase, colonization was further confirmed by 2 confirmatory tests: the CAMP test and the positive latex agglutination test. Next, samples were stored at $-70^{\circ} \mathrm{C}$ for further determination of serotype and antibiotic susceptibility.

Each isolated GBS strain was tested with 7 different antimicrobial agents. Susceptibility to various antimicrobial agents was tested using the antibiotic disk diffusion technique according to the technique described by the National Committee for Clinical Laboratory Standards [28]. The antibiotics tested were: $10 \mu \mathrm{g}$ of ampicillin, 10 units of penicillin, $15 \mu \mathrm{g}$ of erythromycin, $2 \mu \mathrm{g}$ of clindamycin, $30 \mu \mathrm{g}$ of cephalothin, $10 \mu \mathrm{g}$ of gentamicin and $300 \mu \mathrm{g}$ of nitrofurantoin. Each strain had its susceptibility classified as sensitive, intermediate or resistant to each one of these antibiotics.

For serotype identification, the antisera were developed and prepared by inoculating rabbits, according to a previously published method [29]. The GBS strains were classified as one of the serotypes (Ia, Ib, II, III, IV, V) according to their response to the respective antisera. In the case of a lack of response to any of the sera tested, that strain was considered to have an unidentified serotype.

Initially all the variables were studied descriptively by calculating absolute and relative frequencies. To study the association between the categorical variables and the response variable, prevalence ratio was used with a confidence interval of 95\% (CI 95\%). The prevalence ratios with respect to each variable were adjusted according to the others, using Breslow-Cox's regression model. The program used was the SAS ${ }^{\circledR}$ software program, version 8.2.

\section{Results}

Of the 316 parturients included in this study, 46 (14.6\%) were found to be colonized by GBS. The site from which GBS was most frequently isolated was the vagina. Of the total number of positive cultures, 37 derived from the lower vagina, resulting in an accuracy rate for this site of $80.4 \%$. Nine parturients whose vaginal cultures were negative were actually positive for colonization, as confirmed by their anorectal samples. This would have resulted in an error of $19.6 \%$ if only vaginal cultures had been considered. With respect to the rectal site, 26 culture samples were negative for material collected from this site, although samples from the vaginal site of these subjects were positive. The accuracy rate for the rectal site was only $43.5 \%$ and the error rate was $56.5 \%$.

Mean age of the women was 24.3 years $(\mathrm{SD}=6.3)$ and no woman reported having had more than 1 sexual partner in the previous 6 months. The majority were white (59.2\%), married or in a stable relationship (83.5\%), had at least 8 years of schooling (57.6\%) and lived in urban areas (85.8\%). With respect to the obstetric characteristics, the mean gestational age was 38.3 weeks ( $S D=3.3$ ), $43.3 \%$ were primiparous, $20.3 \%$ had premature rupture of membranes and $7.3 \%$ had intrapartum fever (axilar temperature $\geq 37.8^{\circ} \mathrm{C}$ ). There were no statistically significant differences between colonized and non-colonized women (Table 1).

Using the presence of at least 1 risk factor used in the present study (i. e. maternal age $<19$ years; not white; not married; $\leq 8$ years at school; residence in rural area; gestational age < 37 weeks; primigravida; premature rupture of membranes; intrapartum fever) as a predictor of maternal colonization resulted in poor performance. This approach revealed that $83 \%$ of cases were false positives and $13 \%$ were false negatives, resulting in an accuracy rate of $60 \%$ (Table 2).

The antimicrobial susceptibility of the 46 GBS samples is shown in Figure 1. No strain was resistant to penicillin, ampicillin, erythromycin or nitrofurantoin. Eight strains (17.4\%) were found to be resistant to clindamycin, 1 (2.2\%) to cephalothin, and 35 (76.1\%) to gentamicin. Intermediate sensitivity to penicillin and erythromycin was found in $17.4 \%$, to ampicillin in $13 \%$, to gentamicin in $6.5 \%$, to cephalothin in $15.2 \%$ and to nitrofurantoin in $2.2 \%$ of the cases.

Forty-two strains (91.3\%) presented resistance to at least 1 of the antimicrobial agents tested, the majority to gentamicin. Of the 35 gentamicin-resistant strains, 34 were resistant only to gentamicin, and, likewise, of the 8 clindamycin-resistant strains, 6 were resistant only to clindamycin. Of the 35 cases resistant to gentamicin, one was also resistant to clindamycin. Of the 8 cases resistant to clindamycin, only 1 was also resistant to cephalothin. Only 4 strains presented no resistance to any one of the 7 antimicrobial agents tested (data not presented).

Seven different serotypes of GBS were identified in the study and the most frequent was serotype Ib. Of the 46 strains, $24 \%$ belonged to serotype Ib, $19 \%$ to serotype II, and $17 \%$ to serotype Ia. One parturient was harboring more than 1 
serological type of GBS (III and Ia). Serotyping was not possible to be performed in 8 cases (17\%), which were defined as unidentified (Table 3).

No particular serotype presented greater resistance to any specific antibiotic. Eight strains of serotype Ib, 8 of serotype II, 7 of serotype Ia, 3 of serotype IV, 4 of serotype $V$ and 2 of serotype III were resistant to gentamicin. One strain of serotype Ib was resistant to clindamycin.

\section{Discussion}

The prevalence of GBS colonization was $14.6 \%$ in the present study. Rates of GBS colonization varies greatly around

Table 1. Characteristics of the parturients possibly associated to GBS colonization

\begin{tabular}{|c|c|c|c|c|c|c|}
\hline & \multicolumn{4}{|c|}{ Colonization } & & \\
\hline & \multicolumn{2}{|c|}{ Colonized (46) } & \multicolumn{2}{|c|}{ No colonized ( 270$)$} & \multicolumn{2}{|c|}{$\begin{array}{c}\text { Prevalence ratio } \\
\text { CI } 95 \%\end{array}$} \\
\hline & $\mathbf{N}$ & $(\%)$ & $\mathbf{N}$ & $(\%)$ & & \\
\hline \multicolumn{7}{|c|}{ Maternal age (years) } \\
\hline$<19$ & 3 & 6.5 & 52 & 19.3 & 0.33 & $(0.10-1.07)$ \\
\hline$\geq 19$ & 43 & 93.5 & 218 & 80.7 & & \\
\hline \multicolumn{7}{|l|}{ Skin color } \\
\hline White & 27 & 58.7 & 160 & 59.3 & 1.02 & $(0.57-1.84)$ \\
\hline Not white & 19 & 41.3 & 110 & 40.8 & & \\
\hline \multicolumn{7}{|l|}{ Marital status } \\
\hline Married & 39 & 84.8 & 225 & 83.4 & 1.10 & $(0.49-2.45)$ \\
\hline Single & 7 & 15.2 & 45 & 16.7 & & \\
\hline \multicolumn{7}{|c|}{ Education (years at school) } \\
\hline$£ 8$ years & 24 & 52.2 & 158 & 58.5 & 0.80 & $(0.45-1.43)$ \\
\hline$>8$ years & 22 & 47.8 & 112 & 41.5 & & \\
\hline \multicolumn{7}{|l|}{ Residence } \\
\hline Urban & 41 & 89.1 & 230 & 85.2 & 0.73 & $(0.29-1.86)$ \\
\hline Rural & 5 & 10.9 & 40 & 14.8 & & \\
\hline \multicolumn{7}{|l|}{ Gestational age } \\
\hline$<37$ weeks & 8 & 17.4 & 47 & 17.4 & 1.00 & $(0.47-2.15)$ \\
\hline$\geq 37$ weeks & 38 & 82.6 & 223 & 82.6 & & \\
\hline \multicolumn{7}{|c|}{ Number of gestations } \\
\hline Primiparous & 19 & 41.3 & 118 & 43.7 & 1.09 & $(0.61-1.96)$ \\
\hline Multiparous & 27 & 58.7 & & 152 & 56.3 & \\
\hline \multicolumn{7}{|c|}{ Premature rupture of membranes } \\
\hline Yes & 11 & 23.9 & 53 & 19.6 & 1.24 & $(0.63-2.44)$ \\
\hline No & 35 & 76.1 & 217 & 80.4 & & \\
\hline \multicolumn{7}{|c|}{ Intrapartum fever* } \\
\hline Yes & 5 & 10.9 & 18 & 6.7 & 1.55 & $(0.61-3.93)$ \\
\hline No & 41 & 89.1 & 252 & 93.3 & & \\
\hline
\end{tabular}

*Axilar temperature $\geq 37.8^{\circ} \mathrm{C}$.

Table 2. Correlation between the presence of risk factors* and maternal GBS colonization

\begin{tabular}{llll}
\hline \multirow{2}{*}{$\begin{array}{l}\text { At least one of } \\
\text { the risk factors* }\end{array}$} & \multicolumn{2}{l}{ Colonization } & Total \\
\cline { 2 - 3 } & Yes & No & \\
\hline Present & 21 & 102 & 123 \\
Absent & 25 & 168 & 193 \\
Total & 46 & 270 & 316 \\
\hline
\end{tabular}

Sensitivity $=46 \%$. Specificity $=62 \%$. Positive predictive value $=17 \%$. Negative predictive value $=87 \%$. Accuracy $=60 \%$. False positive $=83 \%$. False negative $=13 \%$. *Risk factors considerate: maternal age $<19$ years; not white; not married; $\leq 8$ years at school; residence in rural area; gestational age < 37 weeks; primiparous; premature rupture of membranes; intrapartum fever.
Table 3. Distribution of GBS serotypes isolated in parturients $(n=46)$

\begin{tabular}{ccc}
\hline Serotype & N & \% \\
\hline Ia & 8 & 17.4 \\
Ib & 11 & 23.9 \\
II & 9 & 19.6 \\
III & 2 & 4.3 \\
III and Ia & 1 & 2.2 \\
IV3 & 6.5 & \\
V & 4 & 8.7 \\
NT* & 8 & 17.4 \\
\hline *NT=not typed. & &
\end{tabular}


Figure 1. Distribution of isolated strains according to susceptibility to various antimicrobial agents tested.

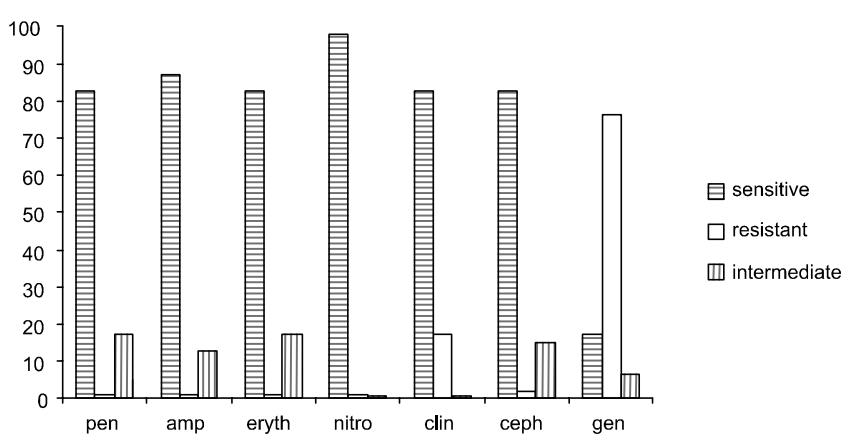

the world, ranging from $4 \%$ to $30 \%$ with a mean of $18 \%$ [30]. In Brazil, there are few studies about the GBS colonization during gestation and they also reported prevalence ranging from $4 \%$ to $28 \%[4,6,10,11]$. Rates of colonization vary according to the origin of the sample, the characteristics of the studied population and the laboratory procedures carried out on the samples [5,31].

Double-sampling (vaginal and rectal) greatly increases the prevalence rate of GBS colonization [10,11,31]. This study also showed that when only rectal samples are collected, $56.5 \%$ of colonized parturients fail to be identified. The vaginal site presented the highest rate of isolation and this data is in agreement with reports from previous studies $[3,5,10]$. Nevertheless, if only vaginal samples are used, we would fail to diagnose colonization in around $20 \%$ of pregnant women. Therefore, the best guidance is still double-sampling, which may be carried out using the same swab, for economical reasons. Care, however, has to be taken to always collect samples from the vaginal region prior to collect from the rectum. Therefore, when requesting laboratory exams for GBS testing, physicians should clarify that double-sampling (vaginal and rectum) should be carried out.

No risk factor was shown to be associated with greater GBS colonization in the present study. The possible risk factors for GBS colonization have been reported in several studies, the largest being the Vaginal Infections and Prematurity Study Group, which also demonstrated that none of the variables studied permitted identification of any group of women more likely of being colonized and that selective screening is, therefore, inefficient [32]. Managing the risk factors, although simple and inexpensive to perform, has a low predictive value and results in a high unwarranted use of antibiotics.

Our data confirm this statement since at least 1 risk factor was present in $39 \%$ of the parturients in this study. The accuracy of risk factors in predicting the need for intrapartum prophylaxis was only $60 \%$. Moreover, the number of falsepositive cases was $83 \%$, which would lead to a high rate of unnecessary antibiotic use and a consequent increase in the risk of developing bacterial resistance. It is therefore crucial to investigate maternal GBS colonization status so that prophylaxis for neonatal infection will be carried out only when it is really necessary.

The prophylaxis currently recommended for optimal prevention of neonatal disease is the intrapartum use of antibiotics only in women known to be colonized by GBS. Penicillin is the first-choice drug, while ampicillin is an alternative and, in cases of history of allergy to penicillin and at high risk for anaphylaxis, clindamycin and erythromycin are recommended [14]. This strategy has been shown to be efficient in reducing neonatal septicemia by GBS [33] and for this reason, it is important to study the GBS resistance profile in the population.

Sensitivity to penicillin has undergone no significant changes in 2 decades and all the strains tested up to the present time have been shown to be sensitive to this antimicrobial agent $[21,22]$. Some authors have described intermediate susceptibility but not resistance of some strains to penicillin $[23,24]$. In the present study, we found no resistance to penicillin, ampicillin, erythromycin or nitrofurantoin. Our failure to find any resistance to erythromycin is not shared by the majority of other publications, whose authors have reported significant rates of resistance to erythromycin and therefore question the CDC recommendation of its utilization as an alternative in cases of allergy to penicillin $[21,24,34,35]$.

Since high sensitivity was also found to nitrofurantoin (97.8\%), this antimicrobial agent may be the drug of choice in cases of urinary tract infections (UTI) caused by GBS in pregnant women. Because UTIs caused by GBS and E. coli may be associated with an increase in the prevalence of premature delivery and premature membrane rupture, treatment of UTIs is essential. The fact that a recent Brazilian study found an association between maternal GBS colonization and the presence of urinary tract infection reinforces the importance of this suggestion [11].

With respect to resistance to clindamycin, the findings of this study are similar to those found in the literature, in which resistance rates of $4 \%$ to $19 \%$ have been reported [24,34,35]. Since clindamycin is another alternative recommended by the CDC for pregnant women who are allergic to penicillin, the high rates of resistance underline the need of carrying out a sensitivity test at least in those with allergy to penicillin. In addition, the adoption of cephalothin would appear to be a good option in sites where the sensitivity test is not available since $82.6 \%$ of GBS strains were sensitive to cephalothin in the present study.

The most frequent serotypes found were Ib, II, and Ia (61\%). Although serotype III was the most common in the majority of studies, this serotype comprised only $4.3 \%$ of the total GBS strains isolated in the present study. Data regarding GBS serotypes in Brazil are limited. In Florianopolis, the most frequent serotypes were II/Ic (Iac+II) and III [5] while in Rio de Janeiro serotypes Ib and Iac were the most prevalent [29]. Further investigations involving a larger number of isolates 
are required to confirm our results related to GBS serotypes in our population.

Nevertheless, the fact that no correlation was observed between serotypes and greatest microbial resistance showed that identifying the serotype is not clinically useful and is not necessary for chemoprophylaxis. It will be important only for the future development of vaccines. Studies with vaccines are in progress but are not a viable short-term option [36].

In conclusion, the results of this study justify the importance of implementing prophylactic strategies since a high prevalence of GBS colonization was found and no risk factors were found that could be useful in identifying colonized pregnant women. These results suggest that specific cultures for the identification of GBS colonization should be carried out in all pregnant women since a positive cost-effectiveness of this action has already been demonstrated in other studies $[11,37,38]$.

The lack of data regarding the true dimension of this problem, which results in the dramatic consequences of neonatal GBS infection, makes it even more serious. The responsability and involvement of the obstetricians in this question is increasing, principally because the situation is preventable. The data from this study, which characterizes the dimension of the problem in the population studied, emphasize the need to elaborate and adopt the most appropriate prophylactic strategies for our population.

\section{Acknowledgments}

The authors would like to thank Dr. Francine Lucente for her help in collecting samples and the microbiologist Priscila Portugal for her help in the microbiological analysis of samples.

\section{References}

1. Edwards M.S., Nizet Z., Baker C.J. Group B streptococcal infections. In: Remington J.S., Klein J.O., Wilson C.B., Baker C.J. Infectious diseases of the fetus and newborn infant. $6^{\text {rd }}$ ed. Philadelphia 2006; $438-98$.

2. Hickman M.E., Rench M.A., Ferrieri P., Baker C.J. Changing epidemiology of group B streptococcal colonization. Pediatrics 1999;104:203-9.

3. Moyo S.R., Mudzori J., Tswana A.S., Maeland J.A. Prevalence, capsular type distribution, anthropometric and obstetric factors of group B Streptococcus (Streptococcus agalactiae) colonization in pregnancy. Cent Afr J Med 2000;46:115-20.

4. Rocha M.L.F., Beltrame L.M.R., Guedes S.C. Prevalência do Streptococcus agalactiae na flora vaginal de gestantes do último trimestre. Rev Bras Patol Clin 1984;20:110-2.

5. Smânia Jr.A., Benchetrit L.C., Smânia E.F.A., Fracalanzza S.E.L. Isolamento de estreptococos do grupo B, de gestantes e neonatos, em Florianópolis, Santa Catarina. Rev Bras Anal Clin 1986;18:103-8.

6. Mocelin C.O., Carvalho D.A.F., Brites C., et al. Isolamento de Streptococcus agalactiae de gestantes na região de Londrina, PR. Rev Bras Ginecol Obstet 1995;17:915-8.

7. Calil R. Estudo de colonização bacteriana em recém-nascidos e controle de bactérias multirresistentes em berçário de alto risco após instituição e controle de medidas de intervenção. Tese de Doutorado, Faculdade de Ciências Médicas, Universidade Estadual de Campinas (UNICAMP), Campinas, SP, Brasil, 2001.

8. Miura E., Martin M.C. Group B streptococcal neonatal infections in Rio Grande do Sul, Brazil. Rev Inst Med Trop São Paulo 2001;43:243-6.
9. Vaciloto E., Richtmann R., Costa H.P.F., et al. A survey of the incidence of neonatal sepsis by group $\mathrm{B}$ streptococcus during a decade in a Brazilian maternity hospital. Braz J Infect Dis 2002;6:55-62.

10. Beraldo C., Brito A.S.J, Saridakis H.O., Matsuo T. Prevalência da colonização vaginal e anorretal por Estreptococo do grupo B em gestantes do terceiro trimestre. Rev Bras Ginecol Obstet 2004;26:543-9.

11. Nomura M.L. Colonização maternal e neonatal por estreptococo do grupo B em gestantes com trabalho de parto prematuro e/ou ruptura prematura pré-termo de membranas. Tese de Doutorado, Faculdade de Ciências Médicas, Universidade Estadual de Campinas (UNICAMP), Campinas, SP, Brasil, 2004.

12. Baker C.J., Edwards M.S. Group B streptococcal infections. In: Remington J., Klein J.O. (eds.). Infectious diseases of the fetus and newborn infant. $4^{\text {th }}$ ed. Philadelphia: WB Saunders, 1995:980-1054.

13. Torres M.O., Sánchez-Pérez H.J., Nazar-Beutelspacher A., et al. Fatores asociados a la colonización por Streptococcus del grupo B en mujeres embarazadas de Los Altos, Chiapas. Salud Pública de Méx 2000;42:1-15.

14. CDC. Centers for Disease Control and Prevention. Prevention of perinatal group B streptococcal disease. Morbidity and Mortality Weekly Report 2002;51(RR-11):1-22.

15. Smaill F. Intrapartum antibiotics for group B streptococcal colonization. In: Cochrane Database Systematic Review 2000;CD000115.

16. Share L., Chaikin S., Pomeranets S., Kiwi R., Jacobs M., Fanaroff A.A. Implementation of Guidelines for Preventing Early Onset Group B Streptococcal Infection. Semin Perinatol 2001;25:107-13.

17. Smaill F. Intrapartum antibiotics for group B streptococcal colonization (Cochrane Review). In: Cochrane Library 2002; Issue 1. Oxford: update software.

18. Rouse D.J., Andrews W.W., Lin F.C., et al. Antibiotic susceptibility profile of Group B Streptococcus acquired vertically. Obstet Gynecol 1998;92:931-4.

19. Silveira D.M., Arkader J., Schirmer J., et al. Gestação de alto risco. $3^{\text {a }}$ ed. Brasília: Ministério da Saúde, 2000.

20. Toresani I., Limansky A., Bogado I., et al. Phenotypic and genotypic study of Streptococcus agalactiae in vagina of pregnant women in Argentina. Medicina 2001;61:295-300.

21. Fracalanzza S.E.L., Benchetrit Jr. L.C. Susceptibilidade de estreptococos do grupo B isolados no período perinatal aos antimicrobianos. Ver Bras Med 1986;43:221-4.

22. Lin F.Y.C., Azimi P.H., Weisman L.E., et al. Antibiotic susceptibility profiles for Group B Streptococci isolated from neonates, 1995. Clin Infect Dis 2000;31:76-9.

23. Betriu C., Gomez M., Sanchez A., et al. Antibiotic resistance and penicillin tolerance in clinical isolates of group B streptococci. Antimicrob Agents Chemother 1994;38:2183-6.

24. Simões J.A., Aroutcheva A.A., Heimler I., Faro S. Antibiotic resistance patterns of group B streptococcal clinical isolates. Infect Dis Obstet Gynecol 2004;12:1-8.

25. Edwards M.S., Baker C.J. Streptococcus agalactiae (Group B Streptococcus). In: Mandell, Bennett and Dolin. Principles and Practice of Infectious Diseases, $5^{\text {th }}$ ed. Philadelphia: Churchill Livingstone, 2000:2156-67.

26. Schuchat A. Epidemiology of group B streptococcal disease in the United States: Shifting paradigms. Clin Microbiol Rev 1998;11:497-513.

27. Zaleznik D.F., Rench M.A., Hillier S., et al. Invasive disease due to group B Streptococcus in pregnant women and neonates from diverse population groups. Clin Infect Dis 2000;30:276-81.

28. NCCLS. National Committee for Clinical Laboratory Standards. Performance Standards for Antimicrobial Disk Susceptibility Tests, Sixth Edition; approved standard. NCCLS document M10A6, vol. 17, no 1, Wayne, PA, 1997. 
29. Benchetrit L.C., Fracalanzza S.E.L., Peregrino H., et al. Carriage of Streptococcus agalactiae in women and neonates and distribution of serological types: a study in Brazil. J Clin Microbiol 1982;15:787-90.

30. Stoll B.J., Schuchat A. Maternal carriage of group B streptococci in developing countries. Pediatr Infect Dis J 1998;17:499-503

31. Schrag S.J., Zell E.R., Lynfield R., et al. A population-based comparison of strategies to prevent early-onset group B streptococcal disease in neonates. N Engl J Med 2002;347:233-9.

32. Regan J.A., Klebanoff M.A., Nugent R.P. For the Vaginal Infections and Prematurity Study Group. The epidemiology of group B streptococcal colonization in pregnancy. Obstet Gynecol 1991;77:604-10.

33. Levine E.M., Ghai V., Barton J.J., Strom C.M. Intrapartum antibiotic prophylaxis increases the incidence of Gramnegative neonatal sepsis. Infectious Diseases in Obstet Gynecol 1999; 7:210-3.
34. Pearlman M.D., Pierson C.L., Faix R.G. Frequent resistance of clinical Group B Streptococci Isolates to clindamycin and Erythromycin. Obstet Gynecol 1998;92:258-61.

35. Silverman N.S., Morgan M., Nichols W.S. Antibiotic resistance patterns of group B streptococcus in antenatal genital cultures. J Reproduct Med 2000;45:979-82.

36. Schrag S.J. The past and future of perinatal group B streptococcal disease prevention. Clin Infect Dis 2004;39:1136-8.

37. Moehe-Boetani J.C., Lineu T.A., Ray G.T., Escobar G. Preventing neonatal group B Streptococcal disease: cost-effectiveness in health maintenance, organization and the impact of delayed hospital discharge for newborns who received intrapartum antibiotics. Pediatrics 1999;103:703-10.

38. Moore M.R., Schrag S.J., Schuchat A. Effects os intrapartum antimicrobial prophylaxis for prevention of group B streptococcal disease on the incidence and ecology of earlyonset neonatal sepsis. Lancet Infect Dis 2003;3:201-13. 